THE KURUME MEDICAL JOURNAL Vol. 18, No. 3, 1971

\title{
RELIEF OF IDIOPATHIC INTENTION TREMOR BY STEREOTAXIC THALAMOTOMY
}

\author{
SHINKEN KURAMOTO AND MITSUO WATANABE \\ Neurosurgical Clinic, Kurume University Hospital \\ Kurume, Japan
}

(Received for publication April 30, 1971)

\begin{abstract}
In 3 cases of idiopathic intention tremor stereotaxic thalamotomy was conducted on the posterior portion of the VL nucleus and the anterior portion of the V. im. e., of the thalamus, and the subthalamic area abutting on these portions, which resulted in abolishment of intention tremor for 8 to 16 months after operation in all the 3 cases treated.
\end{abstract}

Intention tremor is a symptom appearing when an impediment in the dentatorubrothalamic tract arises from various causes. Its characteristic consists of a tremor occurring at the time of movement, whose vibration suddenly rises in amplitude when the voluntary action of the extremities gets near the target.

There is no efficacious medicament for intention tremor, and Cooper ${ }^{1)}$, in 1959, performed stereotaxic VL thalamotomy on patients with intention tremor and confirmed its excellent rsults.
Several reports have been made by authors ever since. We also carried out the stereotaxic thalamotomy on 3 cases of idiopathic intention tremor and could abolish them completely.

\section{CASE REPORTS}

The 3 cases experienced by us are given in Table 1 . All cases presented intention tremor of the extremity which was most pronounced in the right upper limb. Tremor of the neck was a postural one. The trouble lasted for more than 10 years from the onset and disturbed

TABLE 1

Cases of intention tremor

\begin{tabular}{|c|c|c|c|c|c|c|}
\hline \multicolumn{3}{|c|}{ Patients } & \multirow{2}{*}{$\begin{array}{l}\text { Term from } \\
\text { the onset } \\
\text { to surgery } \\
\text { (years) }\end{array}$} & \multirow{2}{*}{ The site of tremor } & \multirow{2}{*}{$\begin{array}{l}\text { Neurological } \\
\text { findings }\end{array}$} & \multirow{2}{*}{$\begin{array}{c}\text { PEG, VAG, CAG, } \\
\text { and EEG }\end{array}$} \\
\hline No. Name & Ages & Sex & & & & \\
\hline 1. T. H. & & $\mathrm{F}$. & 19 & $\begin{array}{l}\text { all the extremities } \\
\text { on both side, neck, } \\
\text { lower jaw, and tongue }\end{array}$ & normal & $\begin{array}{c}\text { within normal } \\
\text { limit }\end{array}$ \\
\hline 2. N. Y. & 32 & M. & 10 & arms and neck & normal & $\begin{array}{c}\text { within normal } \\
\text { limit }\end{array}$ \\
\hline 3. E.M. & 49 & $\mathrm{~F}$. & 15 & arms and neck & normal & $\begin{array}{c}\text { within normal } \\
\text { limit }\end{array}$ \\
\hline
\end{tabular}


patients in their daily activities. With regard to its etiology no causes of intention tremor was found in the family and past histories of all the 3 cases. Since there were no neurologically abnormal findings, and laboratory and radiological examinations were all within normal limits the disease was diagnosed as idiopathic intention tremor (Table 1).

\section{METHODS OF OPERATION}

After the head of a patient was fixed on the stereotaxic apparatus positive pressure pneumoventriculography previously reported by $\mathrm{us}^{2}$ was conducted and the 3 rd ventricle was visualized exactly. The target point was predetermined at a point $3-4 \mathrm{~mm}$ behind the midpoint of a line connecting the commissura anterior (CA) and commissura posterior (CP), $2 \mathrm{~mm}$ above or below the CA-CP line, and $12-13 \mathrm{~mm}$ lateral to the midline of the $3 \mathrm{rd}$ ventricle, and then a stimulating bipolar electrode was inserted as shown in Photos 1, 2, 3 and 4. As soon as the stimulating electrode was placed within the target area intention tremor was suppressed and then with low-frequency stimulation it was checked in 2 cases and augmented in 1 case. The destruction was made using a monopolar electrode of $2 \mathrm{~mm}$ in diameter with a bare tip of $4 \mathrm{~mm}$ as well as with high-frequency current at $70{ }^{\circ} \mathrm{C}$ for 30 seconds. Again the probe was withdrawn $2-3 \mathrm{~mm}$ upward and the same procedure repeated (Photos 1, 2, 3 and 4). As seen on the atlas of Schaltenbrand and Bailey ${ }^{3}$ in Fig. 1, the extent of these therapeutic lesions corresponded to the v. o. p., the posterior portion of the v. o. a. of the VL nucleus and the anterior portion of the V. im. e. of the thalamus, and the subthalamic area abutting on these regions (Fig. 1).

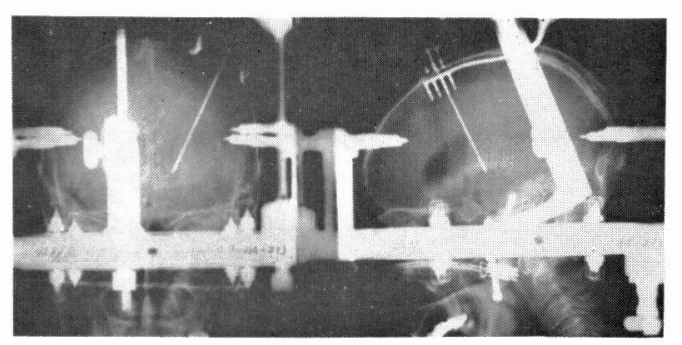

Photo. 1 Case No. 1. (left side)

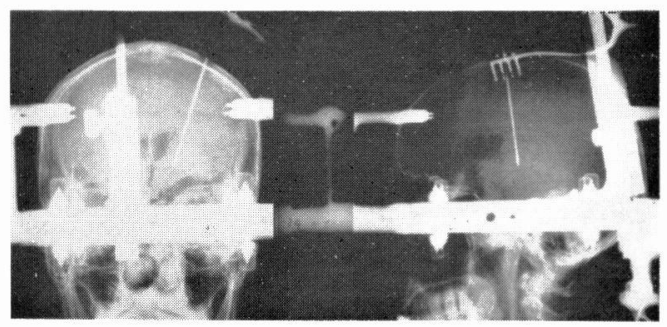

Photo. 3 Case No. 2.

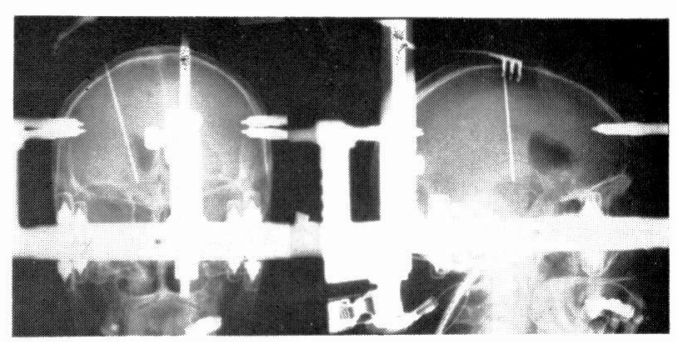

Photo. 2 Case No. 1. (right side)

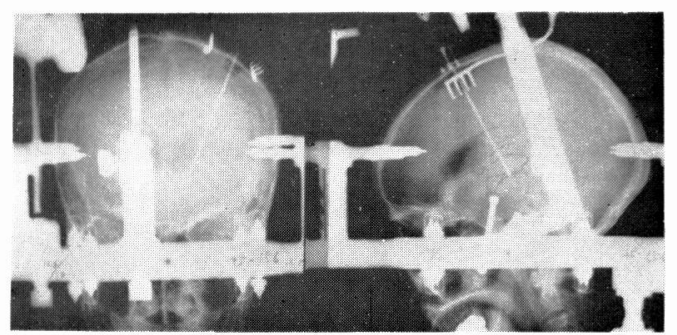

Photo. 4 Case No. 3.

Photos 1-4 X-ray films showing the placement of an electrode in the target point. 


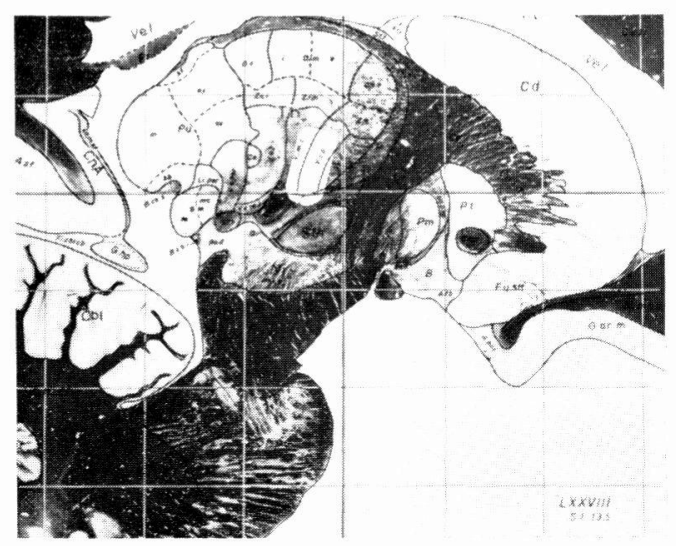

Fig. 1 The extent of destruction on the atlas of human brain by Schaltenbrand and Bailey.

\section{T. ( Na.1 т. ...)}
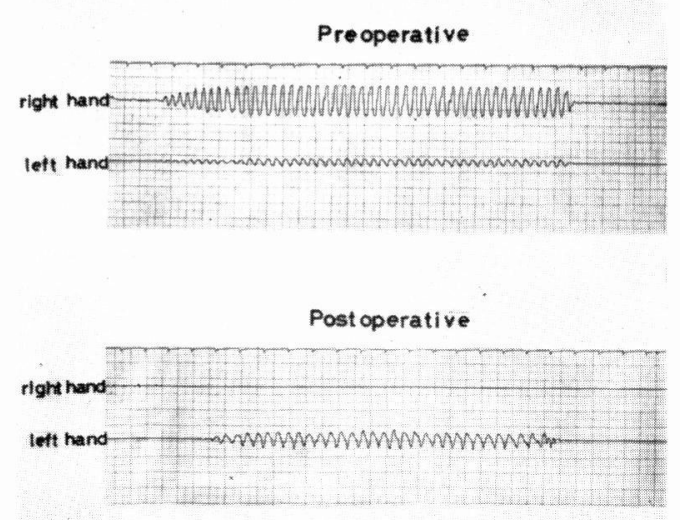

$\sqrt{\sec }$

Fig. 2 Pre- and post-operative minor tremor of case No.1.

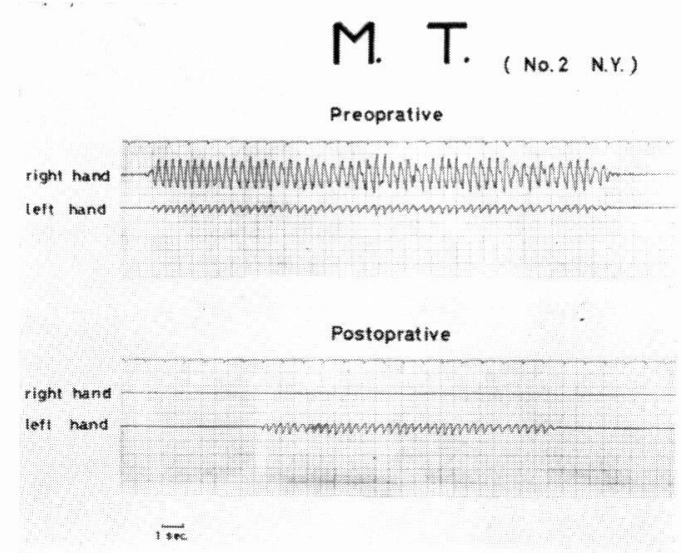

Fig. 3 Pre- and post-operative minor tremor of case No. 2.

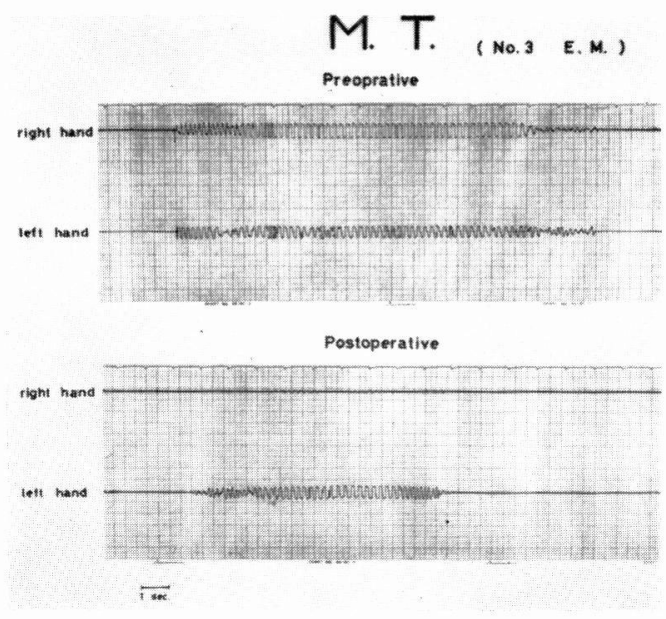

Fig. 4 Pre- and post-operative minor tremor of case No. 3 .

Fig. 2-4 Records of intention tremor in the finger-finger test which was abolished completely after operation.

TABLE 2

Results and side effects of surgery

\begin{tabular}{cc|c|c|c|c}
\hline \multicolumn{2}{c|}{ Patients } & Side of operation & $\begin{array}{c}\text { Results of } \\
\text { operation }\end{array}$ & $\begin{array}{c}\text { Time after } \\
\text { operation } \\
\text { (months) }\end{array}$ & Side effects \\
No. Name & T.H. & $\begin{array}{l}\text { left } \\
\text { right }\end{array}$ & excellent & 16 & $\begin{array}{c}\text { none } \\
\text { good }\end{array}$ \\
2. N.Y. & left & excellent & 8 & $\begin{array}{c}\text { transient choreic } \\
\text { movement and per- } \\
\text { mant dysarthria }\end{array}$ \\
E.M. & left & excellent & 12 & none \\
\end{tabular}




\section{RESULTS}

As seen in Table 2, intention tremor was abolished in all the cases operated. Figs. 2, 3 and 4 show a comparison between the finger-finger test taken before and after operation. On the operated side the intention tremor disappeared completely after operation (Table 2, Figs. 2, 3 and 4). In addition, only through unilateral treatment the tremor of the neck was improved and through bilateral treatment the perfect stopping of tremor observed. In one case undergoing a bilateral operation choreic movement oscurred at the 2 nd operation, which continued for about 3 months and then disappeared, but dysarthria remained permanently.

During 7 to 16 months after operation the operative effect has been kept up well in the same way as just after treatment.

\section{DISCUSSION}

Intention tremor is a symptom occurring due to lesions in the dentatorubrothalamic tract vaused by various degenerative diseases, trauma, tumor of the posterior fossa, cerebrovascular disease, and others. Charaiteristically, intention tremor appears only at the time of voluntary motion of the extremities, which increases rapidly in amplitude when they approach the target. This phenomenon represents a sort of asynergia occurring when a patient wants to correct his dysmetria or overshooting the nearer he gets to the target, for example, it is evident in the finger-nose test or in the heel-shin test.

Experimentally, Walker and Botterell (1937) ${ }^{4)}$ described that unilateral section of the superior cerebellar peduncle in monkeys caused severe ataxia, intention tremor, dysmetria, and decomposition of movement with little or no hypotonia in the ipsilateral limbs.
Carpenter and Stevens (1957) 5' also obtained similar results with the same procedure in monkeys. They noted that the upper limb was more often and more severely affected. They traced the degenerating fibers from the dentate and interposed nuclei of the cerebellum via the dentatorubrothalamic pathway to the contralateral red nucleus, the VL nucleus (via the fasciculus thalamicus), the globus pallidus (via the ansa lentivularis), and the medial longitudinal fasciculus and nearly brain stem nuclei. Carpenter, Glinsman et al.(1958) ${ }^{6)}$ destroyed the dentate and interposed nuclei of monkeys, which led to bradykinesia, ataxia, asynergia, and intention as well as static tremor. Another lesion in the contralateral globus pallidus or fasciculus and ansa lenticularis reduced or abolished both types of tremors 20 days later. They presented the hypothesis that some of the dyskinetic manifestation of cerebellar deficit are dependent upon the integrity of the globus pallidus and its efferent fibers.

Clinically, Cooper (1960) 7) noted that in 6 patients with intention tremor the good results were obtained with a therapeutic lesion involving the medial portion of the VL nucleus of the thalamus, postulating that this resulted from the blocking of the fibers entering the thalamus from the globus pollidus, red nucleus, cerebellum and probably also the vestibular nucleus. Krayenbühl and Yasargil (1962) ${ }^{8}$ reported on the beneficial results of destruction of the anterior portion of the thalamic VL nucleus for intention tremor and stated that this was due to interruption of the dentatorubrothalamic tract and pallidothalamic radiation from flowing into the thalamic VL nucleus. Cooper $(1965)^{3)}$ carried out thalamotomy on 110 cases with intention tremor is produced by a lesion lying between the dentate nucleus and the red nucleus. The thera- 
peutic lesion which abolishes the symptom lies within the thalamus, in a position to interrupt the major portion of impulses arriving by the brachium conjunctivum, either directly from the dentate nucleus or emanating from the dentate nucleus and passing through the red nucleus before arriving in the thalamus. The nuclei which are principally involved by the therapeutic lesion are the anterior portion of the VPL and VPM nuclei, and the posterior portion of the VL nucleus. $\mathrm{He}^{\left.{ }^{9}\right)}{ }^{10}$ ) postulated that intention tremor is caused by faulty feedback of proprioceptive information from the cerebellum to the cortex by way of the thalamus. When this malfunctioning feedback is interrupted by the thalamic lesion other mechanisms evidently supply enough proprioceptive information to the cortex to restore normal modification of motor activity. Obrador and Dierssen (1965) ${ }^{11}$ destroyed various portions in patients with intention tremor, describing that the most effective region of destruction is the VL nucleus of the thalamus and subthalamic area (Forel's field $\mathrm{H}$ ) and that this is due to blocking of the cerebellar tract and the pallidothalamic connection. In 73 cases of intention tremor, Samura, Walz et al. (1970) 12) destroyed the posterior portion of the VL nucleus of the thalamus and the anterior portion of the VPL or VPM adjacent to it and obtained excellent results in 54 cases, good results in 12 cases, slightly good results in 4 cases, and the rest ( 3 cases) remained unchanged.

In our 3 cases of idiopathic intention tremor, it was pronounced in the right upper limb, and a postural tremor of the neck was observed. With unilateral operation intention tremor of the extremities on the contralateral side was abolished completely, and the neck tremor also improved. We destroyed the v. o. p. of the VL nucleus, the anterior half portion of the V. im. e., the posterior portion of the v. o. a. of the VL nucleus, and the subthalamic area abutting on these regions. By means of destruction of the dentatorubrothalamic and dentatothalamic tract in the v. o. p. the tract from the cerebellum was blocked, and, furthermore, the destruction of the v. o. a. blocked the pallidothalamic tract. The V. im. e. of the thalamus is a supravestibular interposed nucleus. According to Narabayashi $(1965)^{13)}$, the destruction of this region proved to be selectively efficacious for parkinsonian tremor, which is thought to have close relation with intention tremor, too. In addition, the destruction of the thalamic nuclei and the subthalamic area adjacent to them seems to block fibers from reaching these nuclei.

\section{REFERENCES}

1) Cooper, I. S. and Poloukheine, N. : Neurosurgical relief of intention (cerebellar) tremor. J. Am. Geriatrics Soc., 7, 443-445, 1959.

2 ) Kuramoto, S. and Watanabe, M. : Experiences on positive pressure pneumoventriculography for stereotaxic surgery.

Kurume Med. J., 17, 145-151, 1970.

3 ) Schaltenbrand, G. and Bailey, P. : Introduction to stereotaxis with an atlas of the human brain. Georg Thieme Verlag, Stuttgart, 1959

4) Walker, A. E. and Botterell, E. M.: The syndrome of the superior cerebellar peduncle in the monkey. Brain, 60, 329353, 1937.

5) Carpenter, M. B. and Stevens, G. H. : Stractural and functional relationships between the deep cerebellar nuclei and the brachium conjunctivum in the rhesus monkey. J. Comp. Neurol., 107, 109-163, 1957.

6) Carpenter, M. B., Glinsman, W. and FABREGA, H. : Effects of secondary pallidal and striatal lesions upon cerebellar dys- 
kinesia. Neurology, 8, 352-358, 1958.

7) CoOper, I. S. : Neurological relief of intention tremor due to cerebellar disease and multiple sclerosis. Arch. Phys. Med., 41, $1-4,1960$.

8) KrayenbüHL, H. and YASARgil, M. G.: Relief of intention tremor due to multiple sclerosis by stereotaxic thalamotomy. Confin. neurol., 22, 368-374, 1962.

9) CoOper, I. S. : Clinical and physiologic implications of thalamic surgery for disorders of sensory communication: II . Intention tremor, dystonia, Wilson's disease and torticollis. J. Neurol. Sci., 2, 520-553, 1965.

10) Cooper, I. S. : Heredofamilial tremor aboli- tion by chemothalamotomy. Arch. Neurol., 7, 129-131, 1962.

11) Obrador, S. and Dierssen, G. : Observations on the treatment of intentional and postural tremor by subcortical stereotaxic lesions. Confin. neurol., 26, 250-253, 1965.

12) Samura, K., Walz, J. M., Diklan, M., KosLOW, M. and CoOPER, I. S.: Relief of intention tremor by thalamic surgery. J. Neurol. Neurosurg. Psychiat., 33, 7-15, 1970.

13) Narabayashi, H.: Physiological analysis of ventrolateral thalamotomy for rigidity and tremor. Confin. neurol., 26, 264-268, 1965. 